\title{
Urethral configuration and mobility during urine leaking described using real-time transperineal ultrasonography
}

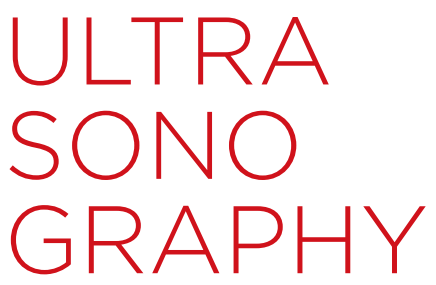

\author{
Baihua Zhao, Lieming Wen, Dan Liu, Shanya Huang \\ Department of Ultrasound Diagnosis, Second Xiangya Hospital, Central South University, \\ Changsha, China
}

\section{ORIGINAL ARTICLE}

https://doi.org/10.14366/usg.21058 pISSN: 2288-5919 - eISSN: 2288-5943 Ultrasonography 2022;41:171-176

Purpose: The aim of this study was to explore differences in the bladder neck configuration and segmental urethral mobility during the cough stress test (CST) in the supine and standing positions between women with and without stress urinary incontinence (SUI).

Methods: This prospective study included 100 control women and 100 incontinent women who had a CST with transperineal ultrasonography. The bladder neck configuration and urethral mobility were described in terms of urethral funneling, bladder neck descent (BND), retrovesical angle (RVA), urethral rotation angle, and urethral mobility at six points along the urethra (vectors 1 to 6). The two groups' ultrasound findings in the two positions were compared.

Results: Valid data were collected from 78 control women and 90 women with SUI. Significant differences were found in age and body mass index between the two groups $(\mathrm{P}<0.01)$. Urethral funneling was found in 33 women (36.7\%) with SUI and five continent women (6.4\%) and altered little in the standing position. In the standing position, the mean RVA significantly increased $\left(160^{\circ}\right.$ to $\left.179^{\circ}, \mathrm{P}<0.001\right)$ in the SUI group; The mean vector of points 1 to 6 significantly increased in the control group (all $P<0.001$ ). The RVA, BND, and vectors 1 to 4 were significantly greater (all $\mathrm{P} \leq 0.01$ ) in women with $\mathrm{SUI}$ than without, in both positions.

Conclusion: Urethral funneling was an intrinsic anatomical characteristic relative to SUI. Weak upper- and mid-urethral support and an unstable connection between the trigone and proximal urethra were the anatomical signs of SUI.

Keywords: Pelvic floor ultrasound; Stress urinary incontinence; Cough stress test; Urethral hypermobility Key points: Transperineal ultrasound can be used to detect bladder neck and urethra's anatomic changes during a cough stress test in supine and standing positions. Stable connection between trigone and proximal urethra was beneficial for continence, and a straightening connection may contribute to leakage. Upper- and mid-urethral mobility was significantly higher in women with stress urethral incontinence (SUI) than continent women, which indicated the weak stability of upper-and mid-urethra in SUI.

\section{Introduction}

Female stress urinary incontinence (SUI) is involuntary urinary leakage that results from increased

This is an Open Access article distributed under the terms of the Creative Commons Attribution NonCommercial License (http://creativecommons.org/ licenses/by-nc/4.0/) which permits unrestricted noncommercial use, distribution, and reproduction in any medium, provided the original work is properly cited.

Copyright (C) 2022 Korean Society of Ultrasound in Medicine (KSUM)

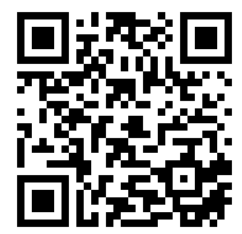

How to cite this article:

Zhao B, Wen L, Liu D, Huang S. Urethral configuration and mobility during urine leaking described using real-time transperineal ultrasonography. Ultrasonography. 2022 Jan;41(1):171-176. 
abdominal pressure during sneezing, coughing, and exercising, with a high prevalence of $20 \%$ and a severe impact on patients' physical and mental health as well as their social relationships [1]. The cough stress test (CST) is a generally used clinical diagnostic test recommended by several clinical practice guidelines for SUI diagnosis $[2,3]$. Evaluating the real-time anatomic changes during urine leaking is vital for understanding the underlying anatomic mechanisms of SUI.

Pelvic floor ultrasonography has been applied to SUI assessment for more than 30 years. When abdominal pressure is increased, the urethra can usually be seen to rotate down around the symphysis pubis. Anatomical changes such as bladder neck mobility, funneling, and segmental urethral mobility can be measured with high reliability [4-7]. A previous study by the authors showed that transperineal ultrasonography (TPUS) could be used to document anatomic changes during the CST in both the supine and standing positions [7].

This study aimed to describe the bladder neck configuration and urethral mobility in the CST in supine and standing positions and to explore the anatomical changes of the urethra in patients with SUI.

\section{Materials and Methods}

\section{Compliance with Ethical Standards}

Data collection was approved by the Human Research Ethics Committee of the Second Xiangya Hospital (No. 2020-038). Informed consent was sought from each subject.

\section{Study Design}

This was a prospective study of 100 incontinent women and 100 control women recruited from a gynecological clinic. All women underwent a standard interview with CST and four-dimensional TPUS between November 2018 and May 2020 at the Second Xiangya Hospital.

Exclusion criteria for the incontinent and control groups were a medical history of (1) previous pelvic or pelvic floor surgery or physiotherapeutic interventions; (2) recurrent infections; (3) voiding symptoms; (4) pelvic irradiation; (5) suspected fistulas; (6) other lower urinary tract symptoms such as urinary frequency, urgency, or dysuria; and (7) pelvic organ prolapse beyond the hymen.

The inclusion criteria for the control group were (1) older than 18 years, (2) no history of neurological and urinary diseases, and (3) not taking any medication.

The inclusion criteria for the incontinent group were (1) a symptom of involuntary urine leakage from physical activity such as coughing, sneezing, or laughing and (2) a positive CST [3]. Based on the interview, the severity of urinary incontinence was classified using the Ingelman-Sundberg scale, as follows: grade I, urinary incontinence when coughing or sneezing; grade II, urinary incontinence when running or picking up items from the floor; and grade III, urinary incontinence when walking or climbing stairs. TPUS was performed using a Voluson E10 system (GE Healthcare, Milwaukee, WI, USA) equipped with a 4-8 MHz curved array transducer placed in the midsagittal direction with the bladder volume less than $50 \mathrm{~mL}$. Ultrasound volumes of the pelvic floor were acquired during CST. Leakage was defined as urine being detected in the urethra or between the external urethral orifice and the probe surface (Fig. 1). Images of at least three Valsalva maneuvers per patient were acquired in both the supine and standing positions, by the authors Zhao and Wen.

Post-processing analysis was performed at least 3 months later in the pelvic floor midsagittal plane by the author Wen, who was blinded to the clinical findings. Urethral funneling was defined as the internal urethral orifice being open during the Valsalva maneuver (Fig. 1). Bladder neck descent (BND), bladder neck position at the maximal Valsalva maneuver (BNP), urethral rotation angle, and the retro-vesical angle were measured according to the American Institute of Ultrasound in Medicine (AIUM)/International Urogynecological Association (IUGA) practice parameter [8].

Urethral segmental mobility was assessed using the semiautomated UMP software [9]. In brief, a semiautomated Excel macro automatically determined the $x$ and $y$ coordinates of six equidistant points placed along the length of the urethra, after manual tracing of the urethra in the midsagittal plane, from the bladder neck (point 1) to the external urethral meatus (point 6), relative to the dorsocaudal margin of the symphysis pubis on a bitmap image (Fig. 1). Segmental urethral mobility (vectors 1 to 6 ) was calculated using the formula SQRT $\left[\left(X_{\text {valsalva }}-X_{\text {rest }}\right)^{2}+\left(Y_{\text {valsalva }}-Y_{\text {rest }}\right)^{2}\right]$.

A test-retest series with a total of 20 patients was performed. The intraclass correlation coefficients (ICCS) of inter-rater agreement were 0.86 for BNP and BND (95\% confidence interval [Cl], 0.78 to $0.96), 0.92$ for the urethral rotation angle $(95 \% \mathrm{Cl}, 0.85$ to 0.97$)$, and 0.91 for the retrovesical angle $(95 \% \mathrm{Cl}, 0.83$ to 0.97$)$. The ICCs for vectors 1 to 6 ranged from $0.76(95 \% \mathrm{Cl}, 0.61$ to 0.84$)$ to 0.93 $(95 \% \mathrm{Cl}, 0.90$ to 0.94$)$, suggesting good to excellent interobserver reproducibility.

Statistical analyses were undertaken using SPSS version 21 (IBM Corp., Armonk, NY, USA). The normality of the continuous data was assessed using the Kolmogorov-Smirnov test. The Wilcoxon test was used for non-normally distributed data. Ultrasound findings in CST in the two positions were compared using the paired t-test, while ultrasound findings in women with and without SUI were compared using the independent t-test. A P-value of $<0.05$ was considered to indicate statistical significance. 


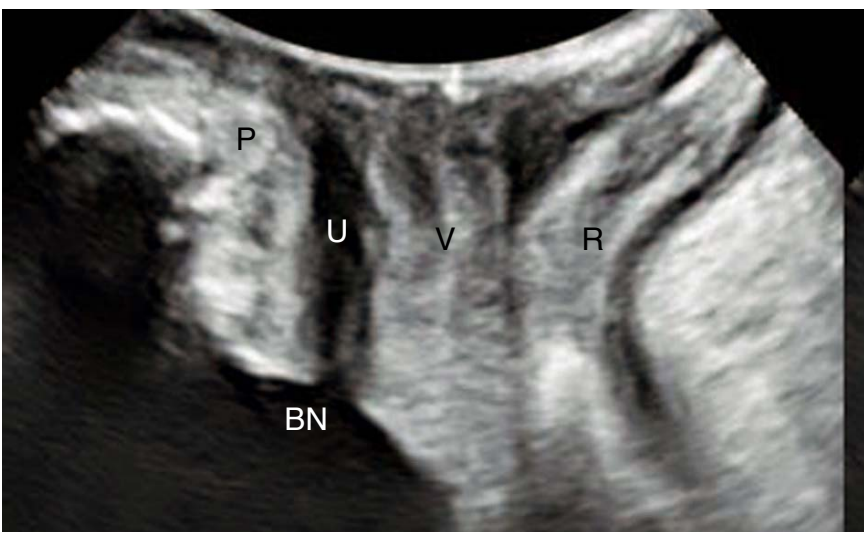

A

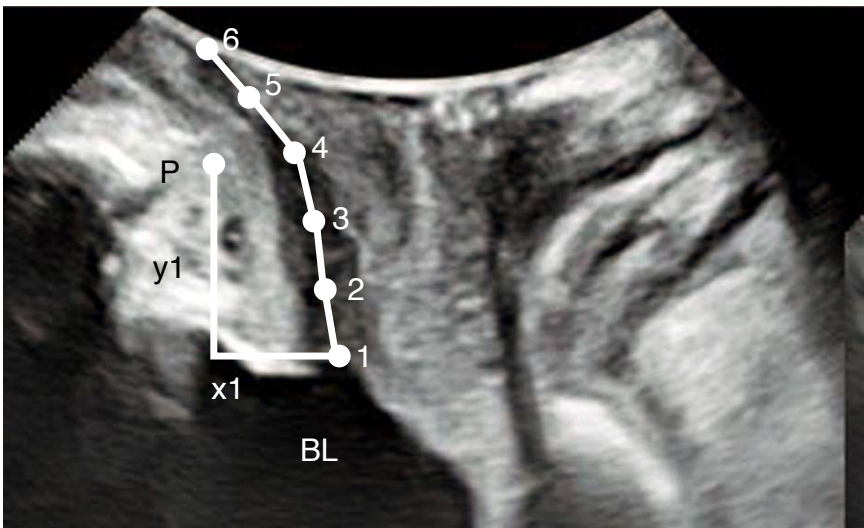

C

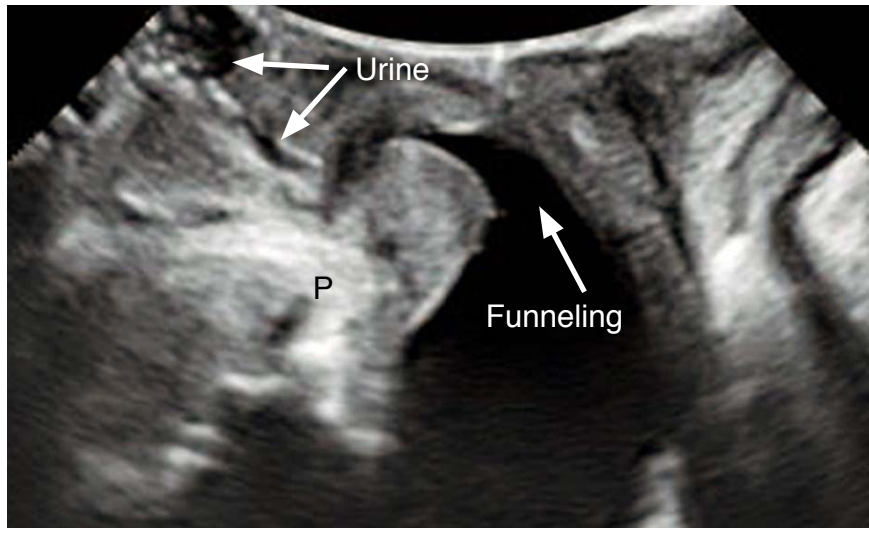

B

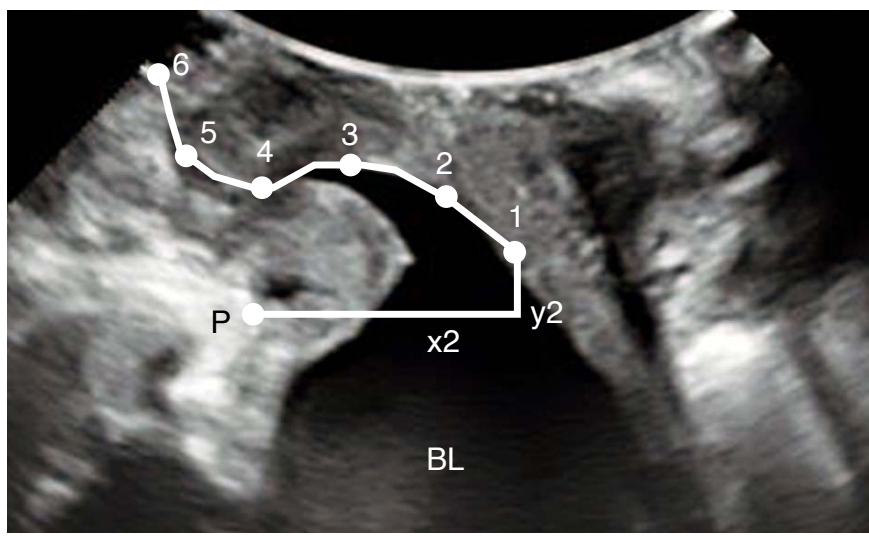

D

Fig. 1. Transperineal ultrasound images in the mid-sagittal plane during real-time urine loss.

$A, B$. Images at rest (A) and the maximal Valsalva maneuver (B) in the supine position are shown. Urine leakage was defined as the presence of urine in the urinary tract or between the external urethral orifice and the probe surface. C, D. Images in the standing position and demonstration of the urethral motion profile by tracing the urethra at rest $(C)$ and during the Valsalva maneuver (D) are shown. Points 1 to 6 were automatically placed, and the $x$ and $y$ coordinates were determined by the UMP software. The vector of point 1 was calculated using the formula: SQRT $\left[\left(x_{2}-x_{1}\right)^{2}+\left(y_{2}-y_{1}\right)^{2}\right]$. BN, bladder neck; $P$, symphysis pubis; $U$, urethra; $V$, vagina; $R$, rectum; $B L$, bladder.

Table 1. Comparison of demographic characteristics between the SUI and control groups $(n=168)$

\begin{tabular}{|c|c|c|c|c|c|}
\hline \multirow{2}{*}{ Characteristic } & \multicolumn{2}{|c|}{ Continent women $(n=78)$} & \multicolumn{2}{|c|}{ SUI women $(n=90)$} & \multirow{2}{*}{ P-value } \\
\hline & Mean \pm SD & Range & Mean \pm SD & Range & \\
\hline Age (year) & $44.1 \pm 4.2$ & $22-71$ & $49.3 \pm 8.0$ & $30-72$ & 0.005 \\
\hline $\mathrm{BMI}\left(\mathrm{kg} / \mathrm{m}^{2}\right)$ & $21.7 \pm 2.9$ & $16.0-31.1$ & $24.1 \pm 2.8$ & $19.0-30.4$ & $<0.001$ \\
\hline Age at first delivery (year) & $24.7 \pm 3.0$ & $20-33$ & $23.8 \pm 3.3$ & $18-33$ & 0.112 \\
\hline Parity $(n)^{a)}$ & $2(1-2)$ & $1-8$ & $2(1-2)$ & $1-6$ & 0.181 \\
\hline
\end{tabular}

SUI, stress urinary incontinence; SD, standard deviation; BMI, body mass index; IQR, interquartile range.

${ }^{a}$ Parity is expressed as median (IQR, Q1-Q3). The P-value is yielded by the Wilcoxon rank test.

\section{Results}

Of the 200 women, 22 control women and 10 incontinent women were excluded because the four-dimensional volume could not be used for UMP analysis. A total of 168 complete datasets were collected from 78 continent women and 90 women with SUI, including 28 women (31.1\%) with grade I SUI, 46 (51.1\%) with grade II, and $17(17.8 \%)$ with grade III, according to the IngelmanSundberg scale.

Significant differences in age $(P=0.005)$ and body mass index 
Table 2. Comparison of ultrasound findings between the SUI and continent groups in the two positions $(n=168)$

\begin{tabular}{|c|c|c|c|c|c|}
\hline \multirow{2}{*}{ Variable } & \multicolumn{2}{|c|}{ SUI women $(n=90)$} & \multicolumn{2}{|c|}{ Continent women $(n=78)$} & \multirow{2}{*}{$\begin{array}{l}\text { Independent } \\
\text { t-test (P-value) }\end{array}$} \\
\hline & Mean $\pm S D$ & Range & Mean $\pm S D$ & Range & \\
\hline \multicolumn{6}{|c|}{ Ultrasound findings in the supine position } \\
\hline Urethral length at rest (mm) & $3.74 \pm 0.41$ & 2.57 to 5.15 & $3.67 \pm 0.39$ & 2.72 to 4.66 & 0.303 \\
\hline Bladder neck position (mm) & $0.81 \pm 7.74$ & -13.0 to 22.0 & $8.38 \pm 8.41$ & -11.0 to 27.0 & $<0.001$ \\
\hline Bladder neck descent (mm) & $27.0 \pm 8.2$ & 4.0 to 42.0 & $19.8 \pm 9.1$ & 0 to 40.0 & $<0.001$ \\
\hline Retrovesical angle $\left(^{\circ}\right)$ & $160.6 \pm 28.7$ & 81 to 268 & $143.2 \pm 25.5$ & 87 to 221 & $<0.001$ \\
\hline Urethral rotation angle $\left(^{\circ}\right)$ & $62.2 \pm 24.6$ & 12 to 131 & $59.9 \pm 26.7$ & 16 to 123 & 0.570 \\
\hline \multicolumn{6}{|c|}{ Ultrasound findings in the standing position } \\
\hline Bladder neck position (mm) & $0.54 \pm 6.14$ & -12.0 to 18.0 & $5.45 \pm 7.88$ & -12.0 to 23.0 & $<0.001$ \\
\hline Bladder neck descent (mm) & $27.3 \pm 7.1$ & 11.0 to 47.0 & $22.8 \pm 8.7$ & 5.0 to 47.0 & $<0.001$ \\
\hline Retrovesical angle $\left({ }^{\circ}\right)$ & $179.1 \pm 21.7$ & 134 to 240 & $145.9 \pm 25.7$ & 40 to 212 & $<0.001$ \\
\hline Urethral rotation angle $\left(^{\circ}\right)$ & $41.7 \pm 24.9$ & 0 to 103 & $42.9 \pm 21.7$ & 4 to 101 & 0.744 \\
\hline \multicolumn{6}{|c|}{ Segmental urethral mobility in the supine position } \\
\hline Point 1 & $3.15 \pm 0.87$ & 1.21 to 5.18 & $2.43 \pm 0.95$ & 0.26 to 4.67 & $<0.001$ \\
\hline Point 2 & $3.01 \pm 0.66$ & 1.53 to 4.28 & $2.40 \pm 0.75$ & 0.60 to 3.90 & $<0.001$ \\
\hline Point 3 & $2.57 \pm 0.52$ & 1.48 to 3.93 & $2.15 \pm 0.61$ & 0.38 to 3.23 & $<0.001$ \\
\hline Point 4 & $2.16 \pm 0.45$ & 1.05 to 3.12 & $1.84 \pm 0.50$ & 0.32 to 2.87 & $<0.001$ \\
\hline Point 5 & $2.12 \pm 0.53$ & 0.82 to 3.12 & $1.82 \pm 0.56$ & 0.28 to 2.95 & $<0.001$ \\
\hline Point 6 & $2.23 \pm 0.59$ & 0.70 to 3.40 & $1.89 \pm 0.63$ & 0.30 to 3.01 & 0.001 \\
\hline \multicolumn{6}{|c|}{ Segmental urethral mobility in the standing position } \\
\hline Point 1 & $3.36 \pm 0.87$ & 1.64 to 5.62 & $2.80 \pm 0.84$ & 1.05 to 4.94 & $<0.001$ \\
\hline Point 2 & $3.13 \pm 0.70$ & 1.57 to 4.53 & $2.72 \pm 0.68$ & 0.97 to 4.21 & $<0.001$ \\
\hline Point 3 & $2.67 \pm 0.58$ & 1.17 to 4.14 & $2.39 \pm 0.58$ & 0.32 to 3.50 & 0.002 \\
\hline Point 4 & $2.21 \pm 0.49$ & 0.82 to 3.84 & $2.02 \pm 0.45$ & 0.96 to 2.96 & 0.011 \\
\hline Point 5 & $2.11 \pm 0.51$ & 0.81 to 3.74 & $1.98 \pm 0.52$ & 0.95 to 3.10 & 0.091 \\
\hline Point 6 & $2.19 \pm 0.56$ & 0.81 to 3.90 & $2.06 \pm 0.62$ & 0.85 to 3.70 & 0.124 \\
\hline
\end{tabular}

SUI, stress urinary incontinence; SD, standard deviation.

(BMI) $(\mathrm{P}<0.001)$ between the two groups were identified using the independent t-test. Eighty-nine (98.9\%) women in the SUI group and $67(85.6 \%)$ women in the control group had at least one vaginal delivery. No significant difference in parity and age at the first delivery was identified between women with and without SUI (Table 1).

In the SUI group, the retrovesical angle $(P<0.001)$ and vector 1 $(P=0.018)$ significantly increased, while the urethral rotation angle significantly decreased $(P<0.001)$ in the standing position relative to the supine position. No significant differences in BNP, BND, and vectors 2 to 6 between the two positions were identified (Table 2). These findings did not change according to the degree of SUI.

For the control group, BNP, BND, and vectors 1 to 6 significantly increased (all $P<0.01$ ). In contrast, the urethral rotation angle significantly decreased $(\mathrm{P}<0.001)$ in the standing position relative to the supine position (Table 2).
Between the two groups, no significant difference was confirmed in urethral length. In the supine position, urethral funneling was found in five continent women (6\%) and in 33 women with SUI (36.7\%); in the standing position, urethral funneling was present in three continent women (3.8\%) and 34 women with SUI (37.8\%). A significant difference $(\mathrm{P}<0.001)$ was identified between the two groups in both positions.

The retrovesical angle, BNP, and BND were significantly greater (all $P<0.001$ ) in the SUI group than in the control group in both the supine and standing positions (Table 2).

Vectors 1 to 4 were significantly greater in the SUI group than in the control group (Table 2) in both positions (all $\mathrm{P} \leq 0.01$ ). The urethral mobility profile of the two groups in both positions is shown in Fig. 2. 
UMP in the supine position

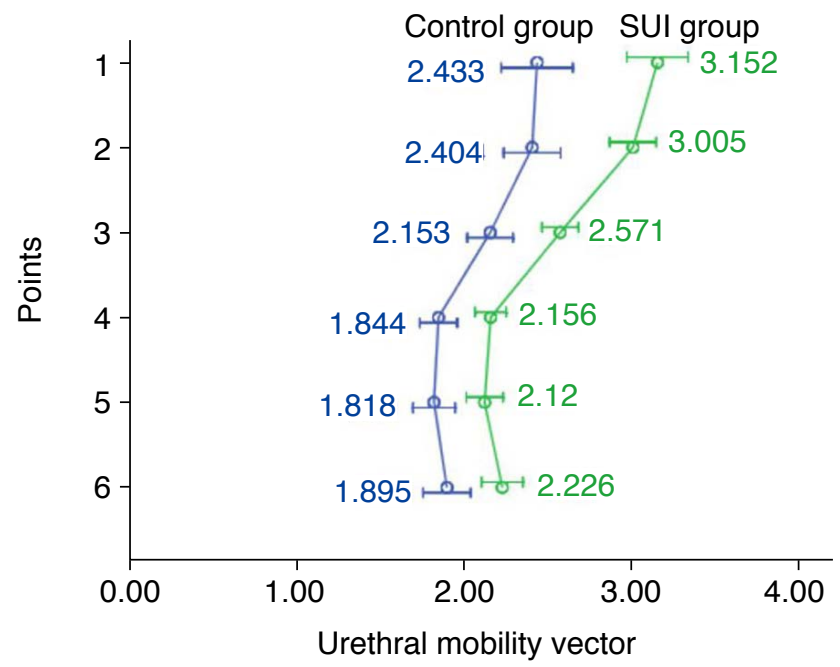

UMP in the standing position

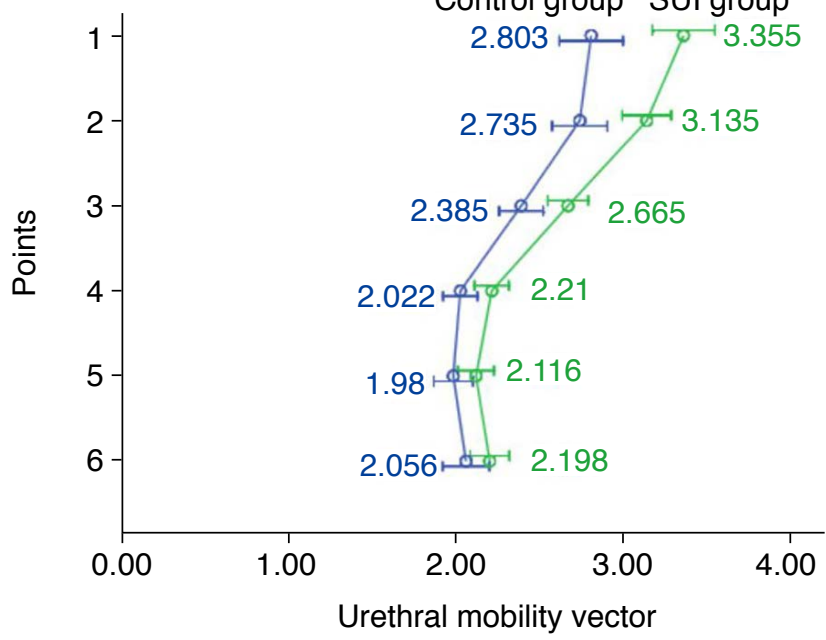

Fig. 2. Urethral mobility profile for women with and without stress urinary incontinence (SUI) in the two positions. Points 1 to 4 show more mobility in the SUI group in both positions.

\section{Discussion}

Pelvic floor ultrasonography is commonly employed to investigate pelvic floor disorders due to its low cost, accessibility, and practicability. TPUS can describe the lower genitourinary structures and the real-time anatomic changes during the Valsalva maneuver. Bladder neck and urethral mobility are usually only documented during the Valsalva maneuver in the supine position $[4,5,9]$. In this study, anatomic changes in the bladder neck and urethra during a CST were observed in the supine and standing positions. For continent women, the mobility of the entire urethra was more significant in the standing position, which indicated that the urethra was subject to considerable pressure. However, the retrovesical angle changed little. Although urethral mobility did not significantly increase in the standing position for incontinent women, the bladder neck and proximal urethral configuration changed. The retrovesical angle increased and was far more oblique. It seems that a stable connection between the trigone and proximal urethra is beneficial for continence, and a straightening connection may contribute to leakage, which agrees with the theory underlying the Green classification of cystocele that an open retrovesical angle is correlated with SUI $[10,11]$.

Furthermore, upper- and mid-urethral mobility was significantly higher in women with SUI than in continent women in both positions, indicating weak stability of the upper-and mid-urethra in SUI. Magnetic resonance imaging demonstrated disruption of the paraurethral ligament in women with SUI [12]. Mid-urethral support damage is an important contributor to SUI $[9,13,14]$.
A markedly higher prevalence of urethral funneling incidence was found in the SUI group. It did not change significantly between the two positions, which indicates that urethral funneling was an intrinsic anatomical characteristic of SUI, in agreement with previous studies [15-17].

$\mathrm{SUI}$ is a multifactorial disease influenced by anatomical structure changes and intrinsic anatomical characteristics, but it can be easily diagnosed by a CST. The suburethral sling/tape implant is an effective surgical procedure, although the incidence of postoperative voiding dysfunction or recurrent SUI is 10\%-20\% $[18,19]$. Therefore, investigating the anatomic changes of SUI may be beneficial for individualizing the surgical strategy [20]. Imaging showing real-time anatomical changes is meaningful.

There are many limitations to this study that need to be acknowledged. First, in this study, urethral sphincter function was not measured using urodynamic tests. Second, the higher BMI in the SUI group may have been a confounding factor in the urethral mobility measurements in the standing position. However, the effect was limited because the mean BMI $\left(24 \mathrm{~kg} / \mathrm{m}^{2}\right)$ in the SUI group was within the non-obese range $[21,22]$. Third, ultrasonography in a standing position best simulates real conditions, but is difficult to perform in practice.

Ultrasound findings during the CST showed that urethral funneling was an intrinsic anatomical characteristic of SUI. Weak upper- and mid-urethral support and an unstable connection between the trigone and proximal urethra were the anatomical signs of SUI.

ORCID: Baihua Zhao: https://orcid.org/0000-0001-7185-292X; Lieming Wen: https:// orcid.org/0000-0003-3283-888X; Dan Liu: https://orcid.org/0000-0002-1852-5396; 
Shanya Huang: https://orcid.org/0000-0001-6500-3024

\section{Author Contributions}

Conceptualization: Wen L. Data acquisition: Zhao B, Wen L, Liu D, Huang S. Data analysis or interpretation: Zhao B, Wen L. Drafting of the manuscript: Zhao B, Liu D, Huang S. Critical revision of the manuscript: Wen L. Approval of the final version of the manuscript: all authors.

\section{Conflict of interest}

No potential conflict of interest relevant to this article was reported.

\section{Acknowledgments}

The authors thank Prof. Ka Lai Shek of Western Sydney University, Australia, for providing the semi-automated UMP software and the related training to Lieming Wen. This study was supported by the National Natural Science Foundation of China (NSFC) project (81901770), Natural Science Foundation of Hunan Province (2020JJ8047) and "The Project of New Clinic Techniques of Central South University".

\section{References}

1. Rubilotta E, Balzarro M, D'Amico A, Cerruto MA, Bassi S, Bovo $C$, et al. Pure stress urinary incontinence: analysis of prevalence, estimation of costs, and financial impact. BMC Urol 2019;19:44.

2. Henderson JW, Kane SM, Mangel JM, Kikano EG, Garibay JA, Pollard RR, et al. A randomized comparative study evaluating various cough stress tests and 24 -hour pad test with urodynamics in the diagnosis of stress urinary incontinence. J Urol 2018; 199:1557-1564.

3. Dmochowski RR, Blaivas JM, Gormley EA, Juma S, Karram MM, Lightner DJ, et al. Update of AUA guideline on the surgical management of female stress urinary incontinence. J Urol 2010;183:1906-1914.

4. Naranjo-Ortiz C, Shek KL, Martin AJ, Dietz HP. What is normal bladder neck anatomy? Int Urogynecol J 2016;27:945-950.

5. Shek KL, Dietz HP. The urethral motion profile: a novel method to evaluate urethral support and mobility. Aust N Z I Obstet Gynaecol 2008;48:337-342.

6. DeLancey JO, Trowbridge ER, Miller JM, Morgan DM, Guire K, Fenner $\mathrm{DE}$, et al. Stress urinary incontinence: relative importance of urethral support and urethral closure pressure. J Urol 2008; 179:2286-2290.

7. Wen L, Zhao B, Chen W, Qing Z, Liu M. Real-time assessment of the behaviour of the bladder neck and proximal urethra during urine leaking in the cough stress test (CST) in supine and standing positions using transperineal ultrasound. Int Urogynecol J 2020;31:2515-2519.
8. AIUM/IUGA practice parameter for the performance of urogynecological ultrasound examinations: developed in collaboration with the ACR, the AUGS, the AUA, and the SRU. J Ultrasound Med 2019;38:851-864.

9. Pirpiris A, Shek KL, Dietz HP. Urethral mobility and urinary incontinence. Ultrasound Obstet Gynecol 2010;36:507-511.

10. Green TH Jr. Urinary stress incontinence: differential diagnosis, pathophysiology, and management. Am J Obstet Gynecol 1975;122:368-400.

11. Chantarasorn V, Dietz HP. Diagnosis of cystocele type by clinical examination and pelvic floor ultrasound. Ultrasound Obstet Gynecol 2012;39:710-714

12. Macura KJ, Thompson RE, Bluemke DA, Genadry R. Magnetic resonance imaging in assessment of stress urinary incontinence in women: parameters differentiating urethral hypermobility and intrinsic sphincter deficiency. World J Radiol 2015;7:394-404.

13. Huang WC, Yang JM. Bladder neck funneling on ultrasound cystourethrography in primary stress urinary incontinence: a sign associated with urethral hypermobility and intrinsic sphincter deficiency. Urology 2003;61:936-941.

14. Petros PE. The pubourethral ligaments: an anatomical and histological study in the live patient. Int Urogynecol J Pelvic Floor Dysfunct 1998;9:154-157.

15. Vazzoler N, Soulie M, Escourrou G, Seguin P, Pontonnier F, Becue $J$, et al. Pubourethral ligaments in women: anatomical and clinical aspects. Surg Radiol Anat 2002;24:33-37.

16. Dietz HP, Clarke B. The urethral pressure profile and ultrasound imaging of the lower urinary tract. Int Urogynecol J Pelvic Floor Dysfunct 2001;12:38-41.

17. Wlazlak E, Kluz T, Surkont G, Kociszewski J. Urethral funneling visualized during pelvic floor sonography: analysis of occurrence among urogynecological patients. Ginekol Pol 2018;89:55-61.

18. Palmieri S, Frigerio M, Spelzini F, Manodoro S, Milani R. Risk factors for stress urinary incontinence recurrence after single-incision sling. Neurourol Urodyn 2018;37:1711-1716.

19. Ripperda CM, Kowalski JT, Chaudhry ZQ, Mahal AS, Lanzer J, Noor $\mathrm{N}$, et al. Predictors of early postoperative voiding dysfunction and other complications following a midurethral sling. Am J Obstet Gynecol 2016;215:656.

20. Dietz HP, Nazemian K, Shek KL, Martin A. Can urodynamic stress incontinence be diagnosed by ultrasound? Int Urogynecol J 2013:24:1399-1403.

21. Zhu L, Li L, Lang JH, Xu T. Prevalence and risk factors for peri- and postpartum urinary incontinence in primiparous women in China: a prospective longitudinal study. Int Urogynecol J 2012;23:563-572.

22. Aune D, Mahamat-Saleh Y, Norat T, Riboli E. Body mass index, abdominal fatness, weight gain and the risk of urinary incontinence: a systematic review and dose-response meta-analysis of prospective studies. BJOG 2019;126:1424-1433. 